\title{
EL DESAJUSTE DEL CRÉDITO EN EL SISTEMA BANCARIO Y LA ACCIÓN DE LA ECONOMÍA SOCIAL: EL CAMINO DE LA REESTRUCTURACIÓN
}

\author{
POR \\ Ricardo PALOMO ZURDO y \\ Milagros GUTIÉRREZ FERNÁNDEZ ${ }^{1}$
}

\section{RESUMEN}

Los cinco años transcurridos desde el inicio de la crisis financiera internacional en el año 2007 han provocado la que, probablemente, sea una de las mayores reestructuraciones del sector bancario realizadas hasta la fecha, tanto en su perspectiva global como en su dimensión doméstica en España. Las entidades de crédito de la Economía Social, cajas de ahorros y cooperativas de crédito, han protagonizado un extraordinario proceso de concentración. Las primeras han sufrido, además, una radical transformación que ha modificado su configuración y naturaleza societaria -mediante la conversión de muchas en bancos- y, consiguientemente, su modelo de negocio y sentido finalista. Desde otra perspectiva, la crisis ha revelado la insuficiencia de las entidades financieras para el ejercicio de su principal misión como entidades suministradoras de crédito. Su amenazada o difícil solvencia, la necesidad de implantar un exigente control del riesgo y las elevadas tasas de morosidad han llevado a una restricción sin precedentes de la actividad crediticia que ha terminado por estrangular a una gran parte de la economía real o productiva. Las tres reformas financieras aprobadas hasta agosto de 2012 han generado cierto "descrédito" entre la sociedad por su elevado coste

\footnotetext{
${ }^{1}$ Ricardo Javier Palomo Zurdo. Universidad CEU San Pablo. Dirección de correo electrónico: palzur@ceu.es Milagros Gutiérrez Fernández. Universidad de Extremadura. Dirección de correo electrónico: mgutierrezf@unex.es

REVESCO Nº 109 - MONOGRÁFICO: La financiación complementaria y la respuesta de la economía social: la situación del "des-crédito" bajo la crisis financiera -

ISSN: 1885-8031 - www.ucm.es/info/revesco

http://dx.doi.org/10.5209/rev_REVE.2012.v109.40653

Fecha de recepción: 20/09/2012

Fecha de aceptación: 05/10/2012
} 
directo e indirecto que se unen al "descrédito" por las restricciones crediticias que la situación del sector y las reformas han impuesto.

Palabras Clave: Crisis financiera, cajas de ahorro, cooperativas de crédito, brecha financiera, descrédito, economía social.

Claves EconLit: G01, G21, G34, P13.

\title{
THE MISMATCH OF CREDIT IN THE BANKING SYSTEM AND THE ACTION OF SOCIAL ECONOMY: THE PATH OF RESTRUCTURING
}

\begin{abstract}
During the last five years, after the beginning of the financial crisis in 2007, one of the major banking restructuring was caused, both in a global perspective and in a domestic dimension for Spain. The credit entities of the social economy, savings banks and credit cooperatives, have led an extraordinary concentration process. The first credit entities, suffered a radical transformation that has modified their corporate structure by converting many of them into banks, and consequently, its business model. From another perspective, the crisis has revealed the failure of financial institutions to fulfill their primary mission as credit entities. Its threatened solvency, the need to implement a strict risk control and the high default rates have led to an unprecedented restriction of lending which has ended up crushing much of the real economy or production. The three financial reforms approved by August 2012 have generated certain "discredit" between society for its direct and indirect high cost that bind to the "discredited" by the credit squeeze that the sector and reforms imposed.
\end{abstract}

Key words: Financial crisis, savings banks, cooperative banks, financial gap, discredit, social economy.

REVESCO No 109 - MONOGRÁFICO: La financiación complementaria y la respuesta de la economía social: la situación del "des-crédito" bajo la crisis financiera -

ISSN: 1885-8031 - www.ucm.es/info/revesco 


\section{INTRODUCCIÓN}

En un contexto como el actual, en el que las entidades bancarias se encuentran ante fuertes dificultades de obtención de recursos, de solvencia y de elevada morosidad, la necesidad de vigilar y también de reactivar su actividad crediticia se ha revelado como la única opción para evitar un mayor deterioro del sistema económico-empresarial.

Las reformas del sector financiero impuestas desde el inicio de la crisis han supuesto más presión para el sector bancario, a lo que se ha añadido la llamada tercera reforma de finales de agosto de 2012.

El coste de estas reformas, la pseudointervención "de facto" de la economía española por aplicación de los fondos de rescate europeos y su efecto sobre el conjunto de la economía y la sociedad, están teniendo un efecto social muy amplio que abunda en un "descrédito" del sector financiero que se suma al "descrédito" por la restricción financiera que se impone a empresas y familias.

La elevada exposición al crédito inmobiliario, con un elevado porcentaje de mora y de fallidos y la fuerte presión que ello supone sobre las cuentas de resultados se ha visto aún más perjudicada por la extensión de la crisis hacia la práctica totalidad de los sectores de actividad.

El exceso de capacidad instalada en el sector, con un claro sobredimensionamiento tanto en entidades como en redes comerciales (Melián y Sanchis, 2009) ha conducido con un ritmo vertiginoso a la consolidación del sector y a una drástica reducción de su cuantía.

Sin embargo, la crisis financiera ha impactado sobre los tres tipos de entidades bancarias de forma muy diversa:

- El sector de la banca se ha visto afectado especialmente en el ámbito de las entidades más centradas en el negocio doméstico. Los grandes bancos, gracias a su amplia internacionalización, han podido diversificar sus riesgos y, aunque también se han visto globalmente afectados (Álvarez, 2008), lo han sido en mucha menor medida.

- Las cajas de ahorros son el segmento más afectado por la crisis; si bien, es cierto que algunas de ellas (una minoría), gracias a una prudente gestión de los riesgos en el

REVESCO No 109 - MONOGRÁFICO: La financiación complementaria y la respuesta de la economía social: la situación del "des-crédito" bajo la crisis financiera -

ISSN: $1885-8031$ - www.ucm.es/info/revesco 
pasado mantienen buenos niveles de solvencia (Bergés y García, 2009). En poco menos de dos años, se ha pasado de 45 entidades a 12 entidades o grupos; en un fuerte proceso de concentración aún inconcluso y que, en la mayoría de los casos ha significado la migración de la actividad que antes desarrollaban como cajas hacia bancos de nuevo cuño, algunos de los cuales han pasado a cotizar en bolsa. En el sector de las cajas de ahorros se han producido diversos episodios de intervención pública que han llevado a la subasta de algunas entidades e, incluso, a su nacionalización ${ }^{2}$, como se detalla posteriormente y ha sido preciso, en la mayoría de los casos, la aportación de ayudas financieras a través del Fondo de Reestructuración Ordenada Bancaria (FROB).

- Las cooperativas de crédito, por el contrario, aunque igualmente han desarrollado un intenso proceso de reagrupamiento, principalmente mediante la formación de sistemas institucionales de protección y/o grupos cooperativos, son las menos afectadas del sector bancario español; pues, si bien, sufren igualmente el deterioro de sus márgenes y de sus ratios, el impacto ha sido menor, gracias a una menor dimensión relativa inicial en los años del crecimiento económico y a una mayor cautela en el sector inmobiliario (Calvo y Paúl, 2010) . En este segmento no ha sido preciso ningún tipo de intervención ni de ayuda financiera pública hasta la fecha (cierre de este documento en septiembre de 2012).

La enorme fragmentación del sector previa a la crisis, hacía necesarios procesos de concentración que redujesen el número de entidades para lograr aumentar su eficiencia (Marco y Moya, 2000) y reforzar su solvencia mediante la introducción de mejoras en sus mecanismos de control y gestión de riesgos; y para garantizar la viabilidad y solidez de las entidades del sistema financiero, incrementando así la confianza de los agentes económicos en el mismo.

El modelo de banca "minorista", centrada en la cercanía al cliente o en el socio, practicado por las entidades bancarias españolas (Palomo y González, 2004), se vio acompañado de un fuerte proceso de expansión geográfica que supuso un

\footnotetext{
${ }^{2}$ Destaca el anuncio de la nacionalización de Bankia el 10 de mayo de 2012.

REVESCO No 109 - MONOGRÁFICO: La financiación complementaria y la respuesta de la economía social: la situación del "des-crédito" bajo la crisis financiera -
}

ISSN: 1885-8031 - www.ucm.es/info/revesco 
sobredimensionamiento de su red de sucursales (Fuentelsaz et al., 2008) y que ha tenido duras consecuencia al llegar la recesión económica.

En este trabajo se trata la situación del sector que ayuda a comprender las dos facetas antes señaladas: el descrédito social por lo ocurrido, en parte como consecuencia de las malas prácticas de algunas entidades; y el "des-crédito" por las graves restricciones a la financiación de empresas, autónomos y familias.

Para ello, se ha estructurado la investigación en cuatro apartados, además de este primero de introducción. El segundo repasa el posible efecto perverso de la excesiva expansión territorial antes de la crisis; el tercero trata la regulación desarrollada desde el inicio de la crisis y su efecto inmediato en diversas entidades; mientras que el cuarto apartado se centra en las operaciones de restructuración y la nueva configuración del mapa bancario de los bancos, cajas de ahorros y cooperativas de crédito. En quinto lugar se presentan las conclusiones del trabajo.

\section{EL EFECTO PERVERSO DE LA EXPANSIÓN TERRITORIAL PREVIA A LA CRISIS FINANCIERA.}

Los años del gran crecimiento económico entre 2001 y 2007 motivaron el planteamiento de varias estrategias de gran calado en el sector bancario:

- Un fuerte desarrollo interno, que se manifestó especialmente en las estrategias de innovación tecnológicas, con el objetivo de incrementar el uso de las TICs y de la banca virtual (Sanchis, 2003).

- $\quad$ Estrategias de mejora de recursos humanos dirigidas a incrementar la eficiencia mediante el aumento de la productividad (Amel et al., 2004).

- $\quad$ Aplicación de políticas de responsabilidad social y gobierno corporativo (Sanchis et al., 2000; Chaves y Soler, 2004; Carrasco, 2005).

- Estrategias de expansión territorial como forma de crecimiento, realizando una creciente apertura de oficinas en nuevas zonas (Palomo y Mateu, 1999).

REVESCO No 109 - MONOGRÁFICO: La financiación complementaria y la respuesta de la economía social: la situación del "des-crédito" bajo la crisis financiera -

ISSN: $1885-8031$ - www.ucm.es/info/revesco 
Según Sanchis y Camps (2003), la extensión de la red de oficinas tiene un valor estratégico superlativo por lo que supone de barrera de entrada a nuevos competidores. Sin embargo, una de sus principales limitaciones es que provoca a corto plazo un fuerte incremento de los costes generales y de personal, al tiempo que es necesario esperar aproximadamente tres años para conseguir una adecuada rentabilización de los puntos de venta creados (Castelló, 1996).

En el caso de las cajas de ahorros y las cooperativas de crédito, este proceso fue muy notorio, como consecuencia del arraigo territorial de las mismas (Palomo, 1999), que ha sido hipotéticamente compatible con un fuerte proceso de expansión geográfica centrado en un modelo de negocio de banca minorista en el que prima la cercanía al cliente.

Cabe destacar, sin embargo, que la expansión fue distinta para las cajas de ahorros y las cooperativas de crédito (Bergés, 2003), pues aunque en ambas se produjo un fuerte incremento en el número de oficinas y empleados, como consecuencia de la desaparición de la limitación legal de actividad financiera para las entidades de ámbito territorial a finales de los años ochenta; el distinto carácter jurídico que las define permitió apreciar diferencias en los procesos de expansión de ambas entidades. Por ejemplo, en el caso de las cooperativas de crédito, dicha expansión, bastante tímida en principio, comenzó por las denominadas "zonas de sombra", y seguidamente abarcó -en un proceso conocido como expansión en forma de "mancha de aceite"- comarcas supuestamente al alcance de otras cooperativas de crédito que, desde ese momento, parecían competidoras (Palomo y Sanchis, 2008).

El contexto de la crisis financiera está poniendo en graves dificultades el mantenimiento de estas extensas redes comerciales (Ruíz, A.), por lo que ya desde 2008 se inició un paulatino proceso de cierre de oficinas.

En la tabla 1 se puede observar el fuerte proceso de crecimiento de oficinas y empleados que experimentaron tanto las cajas de ahorros como las cooperativas de crédito entre los años 1999 y 2008, y cómo, a partir de este año, comienza a reflejarse la reducción de la red que continúa actualmente.

REVESCO No 109 - MONOGRÁFICO: La financiación complementaria y la respuesta de la economía social: la situación del "des-crédito" bajo la crisis financiera -

ISSN: 1885-8031 - www.ucm.es/info/revesco 
Tabla 1: Evolución del número de oficinas y empleados de las cajas de ahorros y cooperativas de crédito hasta el inicio de la crisis financiera (1999-2011)

\begin{tabular}{|c|c|c|c|c|c|c|}
\cline { 2 - 7 } \multicolumn{1}{c|}{} & \multicolumn{3}{c|}{ CAJAS DE AHORROS } & \multicolumn{3}{c|}{ COOP. DE CRÉDITO } \\
\cline { 2 - 7 } \multicolumn{1}{c|}{ Oficinas } & Empleados & Emp/Oficina & Oficinas & Empleados & Emp/Oficina \\
\hline $\mathbf{1 9 9 9}$ & 18.350 & 98.372 & 5,36 & 3.801 & 13.848 & 3,64 \\
\hline $\mathbf{2 0 0 0}$ & 19.297 & 102.989 & 5,34 & 3.947 & 14.466 & 3,67 \\
\hline $\mathbf{2 0 0 1}$ & 19.842 & 106.684 & 5,38 & 4.161 & 15.565 & 3,74 \\
\hline $\mathbf{2 0 0 2}$ & 20.349 & 108.490 & 5,33 & 4.331 & 16.402 & 3,79 \\
\hline $\mathbf{2 0 0 3}$ & 20.893 & 111.105 & 5,32 & 4.520 & 17.058 & 3,77 \\
\hline $\mathbf{2 0 0 4}$ & 21.529 & 113.363 & 5,27 & 4.607 & 17.634 & 3,83 \\
\hline $\mathbf{2 0 0 5}$ & 22.443 & 118.072 & 5,26 & 4.715 & 18.335 & 3,89 \\
\hline $\mathbf{2 0 0 6}$ & 23.457 & 124.139 & 5,29 & 4.822 & 19.334 & 4,01 \\
\hline $\mathbf{2 0 0 7}$ & 24.637 & 131.933 & 5,36 & 5.006 & 20.368 & 4,07 \\
\hline $\mathbf{2 0 0 8}$ & 25.035 & 134.866 & 5,39 & 5.141 & 20.940 & 4,07 \\
\hline $\mathbf{2 0 0 9}$ & 24.252 & 132.340 & 5,46 & 5.079 & 20.722 & 4,08 \\
\hline $\mathbf{2 0 1 0}$ & 23.253 & 128.165 & 5,51 & 5.051 & 20.352 & 4,03 \\
\hline $\mathbf{2 0 1 1}$ & 20.726 & 115.659 & 5,58 & 4.928 & 20.036 & 4,07 \\
\hline
\end{tabular}

Fuente: Elaboración propia a partir de UNACC, CECA y Banco de España (varios años)

\section{LA RE-REGULACIÓN LEGAL DEL SECTOR BANCARIO Y SU EFECTO SOBRE LA ACTIVIDAD CREDITICIA.}

La búsqueda de soluciones para la compleja situación de las entidades financieras ha llevado a una proliferación de normas cada vez más exigentes que tratan de reforzar principalmente la solvencia del sector. Debe tenerse en cuenta que los primeros efectos de la crisis acabaron con las buenas dotaciones a previsiones realizadas en los años de bonanza económica (Torrero, 2008); seguidamente el impacto se sufrió sobre los resultados, y el deterioro pasó a amenazar la última defensa: la solvencia, es decir, la proporción de recursos propios en relación con las operaciones de activo desarrolladas.

En este sentido, las principales normas jurídicas sobre el sector, que trasponen, e incluso adelantan el calendario de aplicación de la nueva regulación internacional son las siguientes:

REVESCO No 109 - MONOGRÁFICO: La financiación complementaria y la respuesta de la economía social: la situación del "des-crédito" bajo la crisis financiera -

ISSN: $1885-8031$ - www.ucm.es/info/revesco 
- Real Decreto-ley 9/2009, de 26 de junio, sobre reestructuración bancaria y reforzamiento de los recursos propios de las entidades de crédito (Constitución del FROB).

- $\quad$ Real Decreto-ley 6/2010, de 9 de abril, de medidas para el impulso de la recuperación económica y el empleo (Regulación de los SIP).

- $\quad$ Real Decreto-ley 11/2010, de 9 de julio, de órganos de gobierno y otros aspectos del régimen jurídico de las Cajas de Ahorros. Esta norma permite a las Cajas ejercer su actividad financiera bien directamente, o bien a través de una entidad instrumental (banco). Este ejercicio indirecto puede realizarse de forma individual o conjunta a través de la creación de un Sistema Institucional de Protección (SIP) entre varias Cajas. Además, el citado Real Decreto-ley ha facilitado los procesos de fusión ordinaria entre Cajas.

- $\quad$ Real Decreto-ley 2/2011, de 18 de febrero, para el reforzamiento del sistema financiero. Esta norma establece un calendario para la recapitalización de las entidades que no alcancen los niveles de capital principal exigidos por la nueva norma ( $8 \%$ de los activos ponderados por riesgo con carácter general, que se eleva al $10 \%$ para aquellos grupos o entidades que no hubiesen colocado al menos un $20 \%$ de su capital entre inversores terceros y tengan un porcentaje de financiación mayorista superior al $20 \%)$.

- $\quad$ Real Decreto-ley 2/2012, de 3 de febrero, de saneamiento del sector financiero, que establece un plan de saneamiento del sector financiero que contempla requerimientos de provisiones y capital adicionales, para cubrir el deterioro en los balances bancarios ocasionado por los activos vinculados a la actividad de promoción inmobiliaria. La norma incorpora incentivos para aquellas entidades que inicien o hayan iniciado desde el 1 de septiembre de 2011 nuevos procesos de integración.

- $\quad$ Real Decreto 18/2012 de 11 de mayo, sobre saneamiento y venta de activos inmobiliarios del sistema financiero.

REVESCO No 109 - MONOGRÁFICO: La financiación complementaria y la respuesta de la economía social: la situación del "des-crédito" bajo la crisis financiera -

ISSN: 1885-8031 - www.ucm.es/info/revesco 
- Real Decreto 24/2012, de 31 de agosto, que se conoce como la norma de la tercera reforma financiera de la crisis, consecuencia del denominado Memorándum de Entendimiento. La norma se articula entorno a la actuación temprana, la restructuración de entidades en dificultades y la resolución de entidades no viables. Crea las figuras de "banco puente" y de "banco malo". En una decisión de política legislativa se asigna al FROB la función de gestión de las crisis bancarias en sustitución del Fondo de Garantía de Depósitos. Se evitan de este modo los solapamientos. El FROB pasa a ser una agencia independiente que rinde cuentas al Parlamento. Debe actuar de forma temprana para evitar que las dificultades de una entidad se contagien al resto, exigiendo, si resulta necesario, la recapitalización y sustitución de administradores. En los casos de dificultades más graves, presentará a la aprobación del Banco de España un plan de reestructuración con apoyo financiero y transmisión de activos y pasivos. Por lo demás, según los criterios internacionales, el coste de la gestión de la crisis debe recaer en los accionistas y acreedores de la entidad en dificultades. De tal modo que, tras los accionistas, son los titulares de participaciones preferentes y bonos subordinados quienes deben asumir las pérdidas. Todos ellos han invertido en una empresa que ha fracasado y deben asumir las pérdidas. Este principio rige con independencia de la responsabilidad por la mala comercialización del producto. Si un inversor adquirió preferentes sin ser informado de la naturaleza y riegos del producto, podrá reclamar al banco comercializador. Como titular de las preferentes con el rescate bancario pierde su inversión, pero dicha pérdida podrá reclamarla a la entidad que le colocó de forma indebida el producto. La lectura del Memorando anima a presentar este tipo de demandas.

En este contexto, cabe añadir un dato significativo de la magnitud del proceso, pues desde octubre de 2008 hasta la primavera de 2012, habían sido cesados o nombrados por distintos motivos 47 Presidentes y 59 Directores Generales de cajas de ahorros.

Con base en los planes de recapitalización derivados del Real Decreto-ley 2/2011, varias entidades optaron por la cotización en Bolsa de sus bancos instrumentales como vía para captar inversores.

REVESCO No 109 - MONOGRÁFICO: La financiación complementaria y la respuesta de la economía social: la situación del "des-crédito" bajo la crisis financiera -

ISSN: 1885-8031 - www.ucm.es/info/revesco 
Hasta la primavera de 2012 eran tres las entidades (anteriores cajas de ahorros) que una vez transformadas en bancos, comenzaron a cotizar en bolsa, las tres en 2011: Caixabank (el 1 de julio de 2011); Bankia (el 20 de julio) y Banca Cívica (el 21 de julio). Con estas operaciones, el $50 \%$ del sector (medido sobre activos totales medios) estaba cotizando en Bolsa, menos de un año después de que la reforma legal lo hiciera posible.

Por otra parte, el Banco de España presentó el 30 de septiembre de 2011 el balance del proceso de recapitalización del sistema financiero. De las 8 entidades pertenecientes al sector de Cajas que precisaban ampliar su capital principal, el resultado fue el siguiente:

- $\quad$ Bankia y Banca Cívica habían obtenido el capital necesario en Bolsa.

- $\quad$ Liberbank y BMN obtuvieron el capital necesario. Para ello, Liberbank optó por la desinversión en una sociedad participada mientras que BMN optó por la colocación de obligaciones convertibles.

- Caja España-Caja Duero había cubierto sus necesidades de capital adicional mediante la integración con Unicaja, aprobada por sus respectivas asambleas el 24 y el 26 de septiembre de 2011.

- $\quad$ Tres Cajas fueron recapitalizadas por el FROB, de acuerdo con lo establecido en el Real Decreto-ley 9/2009.

- NCG Banco precisó una inyección de capital de 2.465 millones $€$, que supuso una participación del FROB en su capital del 93,16\%.

- Catalunya Banc recibió una inyección de capital de 1.718 millones $€$, que supuso una participación del FROB en su capital de 89,74\%.

- Unnim Banc, igualmente necesitó una inyección de capital de 568 millones $€$, que significa una participación del FROB en su capital del $100 \%$ y quedaba como único accionista y administrador del banco. Adicionalmente, se decidió la conversión de las participaciones preferentes convertibles emitidas por Unnim, por importe de 380 millones €, en acciones de Unnim Banc. La Comisión Rectora del FROB formuló, el 7 de marzo de 2012, el plan de reestructuración de Unnim Banc que contempla su

REVESCO No 109 - MONOGRÁFICO: La financiación complementaria y la respuesta de la economía social: la situación del "des-crédito" bajo la crisis financiera -

ISSN: 1885-8031 - www.ucm.es/info/revesco 
integración con BBVA, el cual será titular del $100 \%$ del capital del banco. Esta operación también fue aprobada por el Banco de España y cuenta con el apoyo financiero del Fondo de Garantía de Depósitos de Entidades de Crédito que comprometió la concesión a Unnim Banc de un Esquema de Protección de Activos para garantizar el éxito de su proceso de reestructuración.

- $\quad$ En el caso de Banco CAM, la Comisión Rectora del FROB formuló el 7 de diciembre de 2011 su plan de reestructuración que supuso la integración con Banco Sabadell. Asimismo, la Comisión Gestora del Fondo de Garantía de Depósitos de Entidades de Crédito, de conformidad con el Real Decreto-ley 16/2011, se ha comprometido a aportar los apoyos financieros necesarios para la reestructuración ordenada de Banco CAM.

Este complejísimo escenario, con intervenciones, ayudas financieras y continuas normas reguladoras, ha sido necesario para evitar una situación catastrófica para el sector que habría tenido gravísimas consecuencias para la situación económica española y para su imagen externa; pero, al tiempo, ha supuesto una contracción de la actividad que lleva a una restricción del crédito que debería fluir hacia las empresas o economía real.

De algún modo, el sistema financiero, deja de funcionar correctamente en su principal función de canalización de recursos financieros entre unidades excedentarias y deficitarias, como es habitual en un sistema económico de mercado desarrollado (Calvo et al., 2010).

La incertidumbre sobre la duración de este proceso y la certeza de que se ha creado un círculo vicioso difícil de abandonar complica el horizonte y la salida de la crisis.

El banco central europeo lleva años inyectando liquidez al sistema bancario, pero éste no lo transmite al sector real, pues necesita de ese flujo para su propia supervivencia. Al tiempo, ingentes demandantes de fondos como el propio sector bancario (mediante emisiones de acciones, participaciones preferentes, bonos corporativos, depósitos bancarios, etc.) y los propios estados soberanos (deuda pública) compiten por atraer los ahorros de los ciudadanos, quienes, como consecuencia de la crisis y el desempleo, ven mermada su capacidad de acumular excedentes y comienzan a desconfiar de los prestatarios.

REVESCO Nº 109 - MONOGRÁFICO: La financiación complementaria y la respuesta de la economía social: la situación del "des-crédito" bajo la crisis financiera -

ISSN: 1885-8031 - www.ucm.es/info/revesco 
Estos años han permitido comprobar que el sistema bancario puede quedar bloqueado con efectos devastadores para el conjunto de la economía, y que es necesario gestionar las crisis bancarias con anticipación, restructurando las entidades viables y liquidando de forma ordenada las inviables. En una economía globalizada esta gestión debería ser asumida por una autoridad supranacional.

Cabe plantear que deben ser los accionistas y acreedores de las empresas fracasadas quienes deben asumir las pérdidas, y que, desde el punto de vista de la sociedad, la propia industria bancaria, principal beneficiara del rescate, debería hacerse cargo de la factura final, siendo las ayudas públicas sólo anticipos y facilidades, pero nunca a fondo perdido.

En este sentido España contaba con el Banco de España y el Fondo de Garantía de Depósitos, con capacidad para gestionar las crisis y anticiparse a la manifestación de las dificultades en una actuación temprana. Tenían capacidad para restructurar entidades viables y devolverlas al sector privado una vez saneadas. Además eran los organismos encargados de la liquidación ordenada de las entidades inviables, asegurando en todo caso los depósitos; sin embargo, las sucesivas reformas financieras han ido cambiando ese régimen.

El denominado Memorando del rescate de la banca española del Eurogrupo acabó por imponer en la llamada tercera reforma financiera del 31 de agosto de 2012, los requisitos emanados del G-20 expresados por el Foro de Estabilidad Financiera, que conllevan asignar las funciones de gestión de las crisis bancarias a una autoridad independiente.

\section{EL NUEVO MAPA BANCARIO DE LAS ENTIDADES FINANCIERAS DE ECONOMÍA SOCIAL Y EL DINAMISMO DEL PROCESO.}

Como se ha referido anteriormente, el advenimiento de la crisis financiera a partir del año 2007 ha condicionado completamente el desarrollo reciente del sistema financiero español; si bien, en España, no es hasta el año 2010 cuando se percibe la gran reordenación del sector bancario que la crisis propició.

Dicha reordenación, que ha transformado radicalmente el mapa bancario español y, sobre todo, de las cajas de ahorros (muchas de ellas operando ya a través de bancos) y de las cooperativas de crédito, se ha instrumentado mediante fusiones y adquisiciones $\mathrm{y}$,

REVESCO No 109 - MONOGRÁFICO: La financiación complementaria y la respuesta de la economía social: la situación del "des-crédito" bajo la crisis financiera -

ISSN: 1885-8031 - www.ucm.es/info/revesco 
particularmente, mediante la formación de Sistemas Institucionales de Protección (SIP), una novedosa fórmula de concentración empresarial.

Los SIP surgieron con la Directiva 2006/48/CE, de 14 de junio, de acceso a la actividad de las entidades de crédito, traspuesta al ordenamiento jurídico español a través de diversas normas. En un primer momento, no se pretendía más que dar cabida a grupos de entidades con negocio y actividad homogénea con la facultad de ponderar al $0 \%$ sus riesgos internos, lo que tenía indudables ventajas para la calificación o rating y para otras muchas sinergias. Además, esta fórmula de concentración permite el mantenimiento de cierta independencia jurídica y operativa entre las entidades involucradas, así como la marca comercial. Para su perdurabilidad, el contrato de vinculación obliga en el tiempo, y la comunicación de abandono debe hacerse, al menos, con dos años de antelación. Este sistema se ha ido reforzando en sus aún pocos años de vida, tanto por requerimiento del Banco de España, como por necesidades operativas y de efectividad de los acuerdos.

Los SIP son aplicables a diversos tipos de entidades bancarias, si bien parece adaptarse mejor a las cajas de ahorros y las cooperativas de crédito, por tener una cultura de solidaridad más arraigada. Igualmente, es preciso que sean entidades razonablemente comparables en actividad y modelo de negocio, como ocurre en las citadas, dado su fuerte carácter territorial, su arraigo local y la práctica de un modelo predominante de banca minorista intensivo y extensivo en redes de oficinas (teniendo a las economías domésticas y a la pequeña y mediana empresa como base principal de su negocio). Así mismo, este modelo parece compatible con los principios clásicos de descentralización (autonomía de cada entidad, que ahora tendría restricciones) y subsidiariedad (realizar juntos lo que no se alcanza individualmente).

Los SIP se conocen también como modelos de "fusión fría" o "fusión virtual", pues su planteamiento supone abarcar con amplitud y con criterios de máxima exigencia los múltiples aspectos relacionados con elementos claves como el capital, la solvencia y la política crediticia. Para ello, requieren el establecimiento de un sistema de compromisos internos entre sus integrantes, conforme a la normativa antes indicada y transpuesta al ordenamiento jurídico español en junio de 2008.

REVESCO Nº 109 - MONOGRÁFICO: La financiación complementaria y la respuesta de la economía social: la situación del "des-crédito" bajo la crisis financiera -

ISSN: 1885-8031 - www.ucm.es/info/revesco 
En este sentido, cabe indicar tres enfoques principales vinculados a los objetivos fundamentales de la formación de un SIP:

- El enfoque de la solvencia: los miembros del SIP han de poner en común (mediante un sistema de garantías cruzadas) un porcentaje que puede oscilar entre el 40 y el $50 \%$ de sus recursos propios y que puede alcanzar hasta el $100 \%$ de sus beneficios)

- El enfoque estratégico: para dotar al SIP de estabilidad, las entidades deben aceptar su permanencia en el mismo durante un plazo no inferior a diez años, debiendo realizar un preaviso de dos años si alguna entidad desea plantear su salida, en cuyo caso debería hacer frente a fuertes penalizaciones en forma de mantenimiento de las garantías.

- El enfoque de la dirección y gestión de riesgos: se debe constituir un órgano central con amplias competencias en relación a la política crediticia, al tiempo que debe contar con un plan de eficiencia de obligado cumplimiento por parte de las entidades integrantes.

En definitiva, el SIP se puede entender como un instrumento que fortalece la solvencia y la estabilidad financiera de las entidades integrantes y que pretende mejorar también su eficiencia.

Estos acuerdos no son incompatibles con las fusiones, si bien, dependen del grado de integración que las entidades estén dispuestas a asumir. Los elementos a destacar de un SIP son los siguientes:

- Es un mecanismo de apoyo y defensa mutua.

- Permite el mantenimiento de la identidad y la personalidad jurídica de cada entidad.

- Es una forma de garantizar liquidez y solvencia a sus miembros, por la mejor posición ante el riesgo sistémico y por el apoyo mediante fondos inmediatamente disponibles.

REVESCO No 109 - MONOGRÁFICO: La financiación complementaria y la respuesta de la economía social: la situación del "des-crédito" bajo la crisis financiera -

ISSN: 1885-8031 - www.ucm.es/info/revesco 
- Permite una fórmula mixta de depósito, provisiones, etc. que refuerza las garantías para la calificación externa o rating que, por tanto, mejora y abarata el acceso a la financiación en los mercados financieros.

- Establece un mecanismo de medición consolidada del capital, eliminando la generación cruzada de capital entre sus integrantes y realiza una ponderación del riesgo del $0 \%$ a las exposiciones frente a contrapartes que pertenezcan al mismo SIP que la entidad acreedora, lo que implica que cualquier entidad del SIP puede conceder a otra socia créditos por valor mayor del $25 \%$ de sus recursos propios (artículo 80 de la Directiva 2006/48).

- Incorpora la posibilidad de obtener y gestionar economías de escala y el desarrollo conjunto de nuevos negocios (Morcate et al., 2009).

Las razones que pueden esgrimirse para defender la conveniencia de emprender un proceso de redimensionamiento o reordenación desde el punto de vista económico son múltiples, y van desde la mejora de los niveles de capitalización y de riesgo hasta la búsqueda de la eficiencia y la obtención de economías de escala y alcance (Gutiérrez, 2011).

\subsection{El mapa de los bancos.}

En el sector de la banca, la crisis financiera ha motivado algunas operaciones de concentración en las que se han involucrado tanto a bancos como a cajas de ahorros; siendo algunos de dichos bancos, entidades anteriormente vinculadas a cajas de ahorros, e incluso, nuevos bancos surgidos a partir de anteriores cajas de ahorros (tres de ellos ${ }^{3}$ comenzaron a cotizar en la Bolsa de Valores en julio de 2011).

En este sentido se pueden citar, sucintamente, las siguientes operaciones de concentración protagonizadas por bancos:

- Banco de Valencia, en fase de posible adquisición por parte de Unicaja, al cierre de este trabajo.

- Banco Guipuzcoano, adquirido por Banco de Sabadell a mediados de 2010.

- Banco Pastor, absorbido por Banco Popular a mediados de 2011.

\footnotetext{
${ }^{3}$ Bankia, CaixaBank y Banca Cívica.

REVESCO N 109 - MONOGRÁFICO: La financiación complementaria y la respuesta de la economía social: la situación del "des-crédito" bajo la crisis financiera -
}

ISSN: 1885-8031 - www.ucm.es/info/revesco 
- Bankpyme, adquirido por CaixaBank en septiembre de 2011.

- La Caja de Ahorros del Mediterráneo (CAM), adquirida por Banco de Sabadell a finales de 2011.

- Unnim, el SIP formado por las cajas de ahorros de Sabadell, Terrasa y Manlleu, adquirido por el BBVA en marzo de 2012.

Cabe destacar la fortaleza que han conseguido mantener la mayor parte de los bancos, dada su menor exposición al riesgo del sector inmobiliario, su gestión independiente de los posicionamientos políticos que caracterizaron a las cajas de ahorros y su rápida respuesta para el reforzamiento de su solvencia mediante el recurso a la capitalización a través de los mercados financieros.

Los dos grandes bancos, Santander y BBVA, muy diversificados por su amplia presencia internacional, han mitigado considerablemente el llamado riesgo sistémico de la banca española.

\subsection{El mapa de las cajas de ahorros bajo su nueva configuración bancaria.}

El sector de las cajas de ahorros ha sido, sin duda alguna, el que ha protagonizado el proceso de reestructuración de la banca española. Ello ha sido consecuencia de los mayores desequilibrios, derivados de la expansión crediticia, que registraron en el período previo a la crisis (Gutiérrez et al., 2012). Destaca el exceso de capacidad instalada en el sector y la elevada exposición al sector inmobiliario y constructor, con la consecuente elevación de la tasa de morosidad y la dificultad de acceso a la financiación de los mercados mayoristas ${ }^{4}$.

Como consecuencia de lo anterior, las cajas de ahorros han llevado a cabo la mayor consolidación bancaria realizada en España que, hasta la fecha, se ha concretado en tres fusiones puras y tres por absorción, tres integraciones mediante la modalidad de SIP (uno de los cuales -Bankia- ha sido nacionalizado), dos entidades sin proceso y una caja intervenida en agosto de 2011, la Caja de Ahorros del Mediterráneo (CAM), integrada finalmente con el Banco Sabadell. A lo anterior deben añadirse los procesos acaecidos con anterioridad (entre

\footnotetext{
${ }^{4}$ Precisamente, las fusiones y agrupamientos de cajas de ahorros desarrolladas desde el año 2010 han llevado a la constitución de varios bancos que han recogido el negocio bancario de las cajas que los han originado. Su constitución como sociedades anónimas e incluso su salida a bolsa a partir de junio de 2011 ha sido el modo de transformar su capacidad para ser solventes.
}

REVESCO N 109 - MONOGRÁFICO: La financiación complementaria y la respuesta de la economía social: la situación del "des-crédito" bajo la crisis financiera -

ISSN: 1885-8031 - www.ucm.es/info/revesco 
los que se encuentran la constitución de Banca Cívica, Liberbank y Caja 3 mediante SIP o las fusiones de la Caixa y Caixa Girona, o la de Unicaja con Caja Jaén, entre otras), y las dos cajas rescatadas por el Banco de España en 2009 y 2010, respectivamente: Caja Castilla-La Mancha (CCM) y CajaSur, posteriormente absorbidas por otras entidades. En total, el número de cajas de ahorros se ha reducido de las 45 entidades existentes en diciembre de 2009 a 12 cajas o grupos de entidades en septiembre de 2012. Asimismo, es importante resaltar que dos de ellas han sido adquiridas por Bancos (véase tabla 2), y que casi todas, a excepción de Caixa Ontinyent y Caixa Pollença, han optado por la constitución de bancos para el desarrollo de su actividad financiera.

Tabla 2. Resultados del proceso de concentración de las cajas de ahorros (septiembre de 2012)

\begin{tabular}{|c|c|c|c|c|}
\hline $\begin{array}{l}\text { RANKING } \\
\text { (ATM) }\end{array}$ & $\begin{array}{l}\text { DENOMINACIÓN } \\
\text { ASIGNADA }\end{array}$ & $\begin{array}{l}\text { ENTIDADES } \\
\text { INVOLUCRADAS }\end{array}$ & $\begin{array}{l}\text { TIPO DE PROCESO DE } \\
\text { CONCENTRACIÓN }\end{array}$ & $\begin{array}{l}\text { ACTIVO } \\
\text { TOTAL } \\
(\text { mil. €)* }\end{array}$ \\
\hline 1 & CAIXABANK & $\begin{array}{c}\text { CaixaBank (La Caixa + Caixa } \\
\text { Girona) + Grupo Banca Cívica } \\
\text { (Caja Navarra + Caja Burgos + } \\
\text { Caja General de Canarias + } \\
\text { Cajasol) }\end{array}$ & $\begin{array}{c}\text { FUSIÓN POR ABSORCIÓN } \\
\text { (Previa fusión por absorción de La } \\
\text { Caixa y Caixa Girona, y la } \\
\text { constitución del SIP de Banca Cívica) }\end{array}$ & 361.295 \\
\hline 2 & BANKIA & $\begin{array}{c}\text { Cajamadrid + Bancaja + Insular } \\
\text { Canarias + Laietana + Ávila+ } \\
\text { Segovia + Rioja }\end{array}$ & $\begin{array}{c}\text { SIP } \\
\text { Nacionalizado }\end{array}$ & 344.508 \\
\hline 3 & $\begin{array}{l}\text { PENDIENTE DE } \\
\text { DENOMINACIÓN }\end{array}$ & $\begin{array}{c}\text { Ibercaja + Liberbank (Cajastur } \\
\text { + CCM+ Cantabria + } \\
\text { Extremadura) + Banco Grupo } \\
\text { Caja } 3 \text { (CAI + Caja Círculo } \\
\text { Burgos + Caja Badajoz) }\end{array}$ & $\begin{array}{c}\text { FUSIÓN POR ABSORCIÓN } \\
\text { (Previa constitución de los SIPs de } \\
\text { Liberbank y Caja 3) }\end{array}$ & 118.547 \\
\hline 4 & UNICAJA BANCO & $\begin{array}{l}\text { Unicaja (Unicaja + Caja Jaén) } \\
+ \text { CEISS (Caja España + Caja } \\
\text { Duero) }\end{array}$ & $\begin{array}{c}\text { FUSIÓN POR ABSORCIÓN } \\
\text { (Previa fusión de Unicaja y Caja Jaén, } \\
\text { y Caja España y Caja Duero) }\end{array}$ & 80.381 \\
\hline 5 & KUTXABANK & BBK + Kutxa + Caja Vital & $\begin{array}{c}\text { SIP } \\
\text { (Previa cesión de la totalidad de } \\
\text { activos y pasivos de Cajasur a BKK } \\
\text { en enero de 2011) }\end{array}$ & 79.086 \\
\hline 6 & $\begin{array}{l}\text { NCG BANCO } \\
\text { EVO BANCO }\end{array}$ & Caixa Galicia + Caixanova & FUSIÓN & 78.077 \\
\hline 7 & CATALUNYA BANC & $\begin{array}{c}\text { Caixa Catalunya }+ \text { Tarragona }+ \\
\text { Manresa }\end{array}$ & $\begin{array}{c}\text { FUSIÓN } \\
\text { Nacionalizado y pendiente de subasta }\end{array}$ & 76.649 \\
\hline 8 & $\begin{array}{l}\text { GRUPO BANCO } \\
\text { MARE NOSTRUM }\end{array}$ & $\begin{array}{l}\text { Caja Murcia + Penedés + Sa } \\
\text { Nostra + Granada }\end{array}$ & SIP & 71.723 \\
\hline 9 & BANCO CAM & CAM & $\begin{array}{c}\text { INTERVENIDO } \\
\text { e integrado con Banco Sabadell }\end{array}$ & 70.666 \\
\hline 10 & UNNIM BANC & $\begin{array}{c}\text { Caixa Sabadell + Terrasa + } \\
\text { Manlleu }\end{array}$ & $\begin{array}{c}\text { FUSIÓN } \\
\text { Nacionalizado e Integrado con BBVA }\end{array}$ & 28.550 \\
\hline 11 & CAIXA ONTINYENT & Caixa Ontinyent & Sin proceso & 980 \\
\hline 12 & $\begin{array}{l}\text { COLONYA CAIXA } \\
\text { POLLENÇA }\end{array}$ & Colonya Caixa Pollença & Sin proceso & 344 \\
\hline
\end{tabular}

* Las cifras de activos totales hacen referencia al año 2011 por ser éste el último del que se disponen datos oficiales.

Fuente: Elaboración propia a partir de comunicados de las entidades y prensa económica.

REVESCO No 109 - MONOGRÁFICO: La financiación complementaria y la respuesta de la economía social: la situación del "des-crédito" bajo la crisis financiera -

ISSN: $1885-8031$ - www.ucm.es/info/revesco 
Como puede verse en la tabla 2, una de las fórmulas más utilizadas en la reordenación bancaria ha sido la de los sistemas institucionales de protección (SIP), en la que los integrantes mantienen su identidad propia y su capacidad operativa en el plano comercial, así como su independencia económica, pero poniendo en común en diverso grado su solvencia y resultados de la actividad (Palomo et al., 2011). La utilización de dicha modalidad de concentración ha permitido la realización de integraciones interregionales, que en el pasado hallaban dificultades por la politización de las cajas de ahorros.

La excepcionalidad y dimensión de este proceso -el mayor y más intenso en la historia bicentenaria de estas entidades- centra el interés en analizar si los agrupamientos culminados o proyectados han seguido criterios de homogeneidad en su modelo de negocio, tal y como recomienda el Banco de España para la constitución de los Sistemas Institucionales de Protección (SIP), dado que, el supervisor considera imprescindible que los nuevos grupos de entidades surgidos tras el reordenamiento del sector, sigan siendo eficientes y ganen en competitividad para continuar desempeñando la importante función financiera y social que les corresponde.

En este sentido, diversos estudios (Palomo et al., 2011; Gutiérrez, 2011) demuestran la hipótesis de que los procesos de integración acaecidos en el sector de las cajas de ahorros no responden a cuestiones de homogeneidad en el modelo de negocio de las entidades constituyentes como habría sido deseable y recomendado por la normativa y el supervisor; sino que han sido otros los criterios que han guiado la reestructuración del sector (cuestiones personales, políticas, administrativas, valoraciones del mercado y de analistas, e incluso, la propia orientación del supervisor).

\subsection{El mapa de las cooperativas de crédito: dinámica del proceso.}

El mapa de las cooperativas de crédito españolas se ha visto radicalmente transformado desde el año 2009.

La entrada en escena de los agrupamientos en forma de Sistema Institucional de Protección (SIP) y de Grupos Cooperativos, así como determinadas fusiones, han desbordado

REVESCO No 109 - MONOGRÁFICO: La financiación complementaria y la respuesta de la economía social: la situación del "des-crédito" bajo la crisis financiera -

ISSN: 1885-8031 - www.ucm.es/info/revesco 
los tradicionales ámbitos territoriales de carácter provincial o comarcal. De hecho, la figura de los grupos cooperativos venía recogida ya en la Ley 27/1999, de Cooperativas (Art. 78). ${ }^{5}$

Las cooperativas de crédito fueron pioneras en España para la aplicación de esta fórmula de concentración; concretamente fue el SIP de Cajamar el primero en ser autorizado por el Banco de España, en diciembre de 2009.

Según los últimos datos disponibles al cierre de este trabajo, había un censo de 74 entidades, con 4.928 oficinas y 20.036 empleados. Cuentan con cerca de 2,5 millones de socios. Todo ello supone una dimensión superior a los 127.000 millones de euros de activos totales. Los depósitos del sector ascienden a 81.132 millones de euros y los créditos a 98.359 millones de euros.

Los procesos acaecidos desde 2009 permiten hablar de 48 entidades o grupos consolidables.

En este contexto, el advenimiento de la crisis financiera entre los años 2007 y 2008, coincidió con un proceso de reorganización que ya años antes parecía gestarse, y cuyo máximo exponente había sido veinte años atrás, la constitución, en el año 1989, del Grupo Caja Rural, dotado del Banco Cooperativo Español S.A. y de otras entidades especializadas como la compañía de seguros RGA y la de servicios tecnológicos RSI. Este modelo, conformado en torno a la Asociación Española de Cajas Rurales (AECR), llegó a aglutinar a la práctica totalidad del sector y se construyó bajo los principios de subsidiariedad, solidaridad interna y centralización de determinadas funciones; en definitiva, lo que se ha denominado un modelo de "cooperación reforzada". La dimensión agregada de los miembros de la AECR alcanza en 2011 las 3.600 oficinas y 13.000 empleados, con unos activos de más de 59.000 millones de euros y unos fondos propios de más de 4.700 millones.

Ahora bien, los diversos intentos de llegar a un modelo de mayor concentración y cohesión, planteados desde el año 2001, la propia evolución interna del sector y las recomendaciones del Banco de España, pusieron sobre la mesa la posible aplicación de la normativa europea del año 2006 sobre los sistemas institucionales de protección. Ese proceso

\footnotetext{
${ }^{5}$ La ley 27/1999, define un grupo cooperativo como un conjunto de cooperativas alrededor de una entidad cabeza de grupo que ejerce facultades o emite instrucciones de obligado cumplimiento para las cooperativas agrupadas dando lugar a un modelo con unidad de decisión.
}

REVESCO Nº 109 - MONOGRÁFICO: La financiación complementaria y la respuesta de la economía social: la situación del "des-crédito" bajo la crisis financiera -

ISSN: 1885-8031 - www.ucm.es/info/revesco 
evolutivo, unido a las nuevas circunstancias del conjunto del sector financiero global a partir del año 2008, se convirtieron en el escenario que sentaría las bases del actual, y aún inconcluso, mapa de las cajas rurales españolas.

Entre los años 2000 y 2008 se producen diversos procesos de fusiones entre cooperativas de crédito, recogidos en la tabla 3; si bien, es en 2009-2010 cuando se inicia la actual reordenación del sector.

Tabla 3. Fusiones entre Cajas Rurales (2000-2008) previas a la reordenación iniciada en 2009.

\begin{tabular}{|l|l|l|l|l} 
Año & \multicolumn{1}{|c|}{$\begin{array}{c}\text { Entidad fusionante } \\
\text { absorbente }\end{array}$} & \multicolumn{1}{|c|}{$\begin{array}{c}\text { Entidad fusionada o } \\
\text { absorbida }\end{array}$} & \multicolumn{1}{|c|}{$\begin{array}{c}\text { Operación } \\
\text { Comunidad } \\
\text { Autónoma }\end{array}$} \\
2000 & CR Huesca & CR Segre-Cinca & Absorción & Varias \\
\hline 2000 & CR Málaga & Caja Grumeco & Absorción & Varias \\
\hline 2000 & CR Almería (Cajamar) & CR Málaga & Absorción & Andalucía \\
\hline 2001 & Credicoop & CR Benicassim & Cesión & C. Valenciana \\
\hline 2001 & Credicoop & CR Cabanes & Cesión & C. Valenciana \\
\hline 2001 & Credicoop & CR Artana & Cesión & C. Valenciana \\
\hline 2001 & CR Huelva y CR Sevilla & CR del Sur & Fusión & Andalucía \\
\hline 2002 & CR Valencia (Ruralcaja) & $\begin{array}{l}\text { CR Alicante } \\
\text { Credicoop }\end{array}$ & $\begin{array}{l}\text { Absorción } \\
\text { Absorción }\end{array}$ & C. Valenciana \\
\hline 2002 & CR Huesca y CR Zaragoza & CR Aragonesa y Pirineos & Fusión & Aragón \\
\hline 2002 & CR Aragón & CR Campo Cariñena & Absorción & Aragón \\
\hline 2003 & CR Navarra & Cobanexpo & Absorción & Varias \\
\hline 2004 & Ruralcaja & Caja Elche & Absorción & C. Valenciana \\
\hline 2008 & Cajamar & CR Duero & Absorción & Varias \\
\hline
\end{tabular}

Fuente: Palomo R.; Sanchis, J.R. (2010)

El reciente fenómeno de agrupamiento de la banca cooperativa española, el mayor y más profundo o comprometido de su historia, coincide de forma evidente con la reordenación bancaria internacional provocada por la crisis financiera mundial; si bien, ésta ha sido, más bien, el catalizador o acelerador del cambio de modelo de cooperación intrasectorial que, desde años atrás, parecía aconsejable para la adecuada evolución del sector.

De las 81 entidades existentes a finales de 2008 se ha pasado a 74 al cierre de este trabajo; si bien, muchas de ellas agrupadas en torno a SIP; con la previsión de que el número de entidades o grupos quede en 40 ó 45 en pocos años, e incluso antes de lo esperado. En todo caso, este proceso puede no ser suficiente y es preciso superar recelos y personalismos que primen la finalidad para los socios sobre los intereses particulares.

REVESCO N 109 - MONOGRÁFICO: La financiación complementaria y la respuesta de la economía social: la situación del "des-crédito" bajo la crisis financiera -

ISSN: 1885-8031 - www.ucm.es/info/revesco 
El panorama actual (septiembre de 2012) de las cooperativas de crédito españolas se puede sintetizar del siguiente modo, contando con 4 grupos consolidables y otros procesos de fusión a partir de 2009:

1. El Grupo Cajas Rurales Unidas, constituido el 17 de enero de 2012 por la unión de dos grandes grupos del sector: el Grupo Cajamar y el Grupo Cajas Rurales del Mediterráneo, formados, a su vez, como se describe seguidamente:

- El Grupo Cajamar ${ }^{6}$, constituido oficialmente en diciembre de 2009 -el primer SIP creado en España-. Originalmente compuesto por Cajamar Caja Rural, Caja Campo, Caja Rural de Casinos y Caixa Albalat, al que se añadió Caja de Petrer, Caja de Turís y, en diciembre de 2011, incluyendo también la absorción de Caja Rural de Castellón). El Banco de España lo catalogó como "grupo consolidable de entidades de crédito" bajo la forma de Sistema Institucional de Protección (SIP). Cajamar absorbió a C.R. Balears en el verano de 2010; pero previamente, en 2008, había absorbido a C.R. del Duero.

- El SIP Cajas Rurales del Mediterránero (CRM), aprobado por el Banco de España en otoño de 2010 y formado por 15 cajas rurales, siendo la mayor de ellas la valenciana Caja Rural del Mediterráneo. Este SIP proyectaba integrarse, a su vez, en el SIP en constitución de las cajas vinculadas desde hace años a la Asociación Española de Cajas Rurales (AECR) que cuentan con el Banco Cooperativo Español como entidad bancaria de servicios centrales. Sin embargo, en diciembre de 2011 las negociaciones estaban estancadas y, contra todo pronóstico, el Grupo CRM acordó su vinculación al Grupo Cajamar, ratificado por sus asambleas generales a mediados de enero de 2012. Por tanto, estos dos SIPs han quedado agrupados por fusión en una nueva entidad: Cajas Rurales Unidas, actualmente el máximo exponente en dimensión de la banca cooperativa española.

2. El Grupo Cooperativo Solventia, constituido en julio de 2011, que con Cajalmendralejo al frente vincula a otras cinco cajas rurales andaluzas. Este grupo

\footnotetext{
${ }^{6}$ Un Grupo Cooperativo de Crédito es en esencia un Sistema Institucional de Protección (SIP), consolidable a efectos contables, pero no realiza mutualización total de los resultados del conjunto de las entidades involucradas.
}

REVESCO Nº 109 - MONOGRÁFICO: La financiación complementaria y la respuesta de la economía social: la situación del "des-crédito" bajo la crisis financiera -

ISSN: $1885-8031$ - www.ucm.es/info/revesco 
destaca en esa fecha por su elevado core capital del 15,5\% (casi el doble del obligatorio), un coeficiente de solvencia del 17,04\% y una baja morosidad del 2,06\%.

3. El Grupo Cooperativo Ibérico de Crédito, formado por tres cajas rurales: C.R. de Extremadura, C.R.de Córdoba y C.R. del Sur.

4. Globalcaja, resultado de la fusión de las cajas rurales de Ciudad Real, Cuenca y Albacete. A su vez, C.R. Albacete absorbió en 2010 a C.R. de Roda.

5. Bantierra (Nueva Caja Rural de Aragón), producto de la fusión de Multicaja y Cajalón. A su vez Multicaja absorbió a Caja de Abogados en 2009.

6. La caja rural de Burgos, Fuentepelayo, Segovia y Castelldans, Sociedad Cooperativa de Crédito; resultante de la fusión, en marzo de 2012, de las cajas rurales de Fuentepelayo, Burgos, Segovia y Castelldans.

7. La entidad resultante de la integración de Caja Laboral Popular e Ipar Kutxa, anunciada en junio de 2012.

Con el fin de apreciar el dinamismo de estos procesos en el breve espacio temporal que se han producido, las siguientes figuras tratan de resumir esa evolución a modo de instantáneas del sector en determinadas fechas en que se realizaban los acuerdos de concentración o agrupamiento. Puede apreciarse también el abandono de algunas iniciativas y el surgimiento de otras diversas a las que se pretendían originar.

REVESCO No 109 - MONOGRÁFICO: La financiación complementaria y la respuesta de la economía social: la situación del "des-crédito" bajo la crisis financiera -

ISSN: 1885-8031 - www.ucm.es/info/revesco 
Figura 1.A

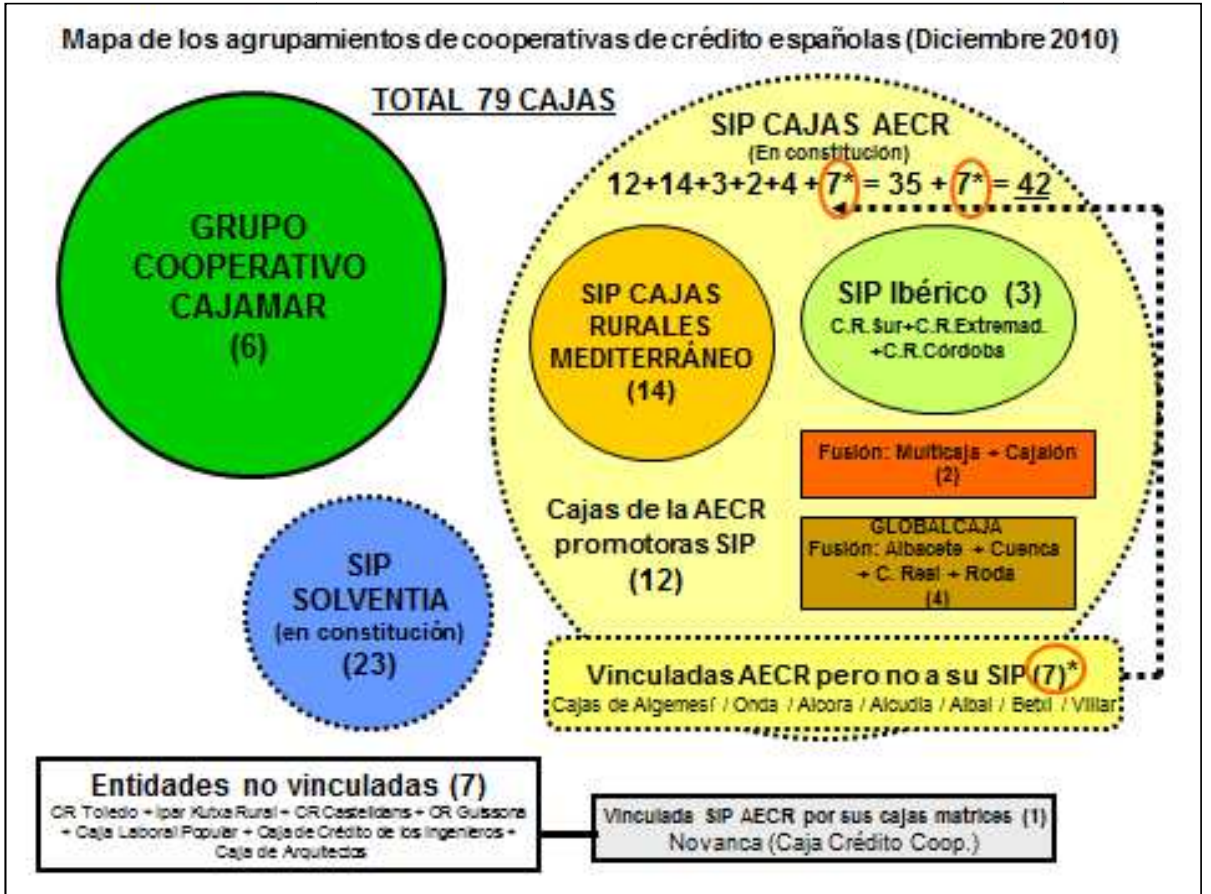

Fuente: elaboración propia.

Figura 1.B

Mapa de los agrupamientos de cooperativas de crédito españolas (Febrero 2011)

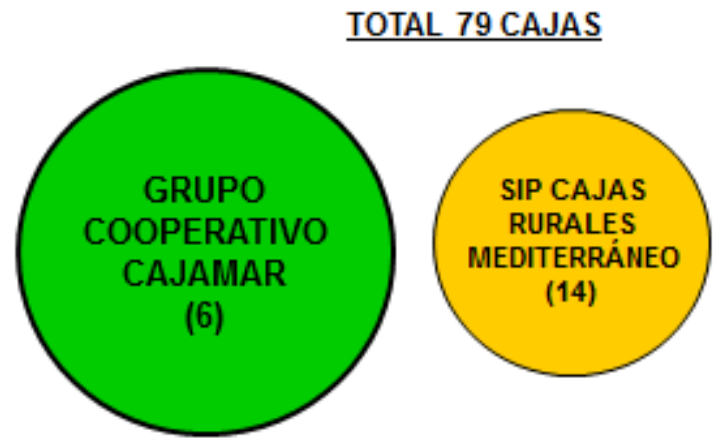

Cajas de la AECR no vinculadas a SIP (44)

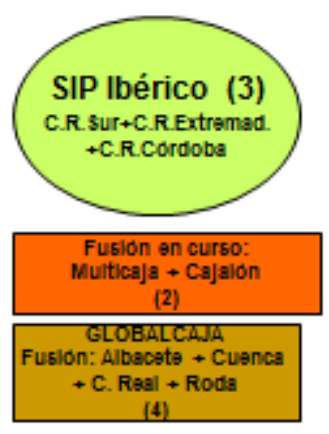

\section{Entidades no vinculadas (6) \\ los Kuss Rursi + CR Cossedss + CR Gursors \\ - caja Laboral Poujer + Cajade Credto de los ingenteros- Caja de Avqutedas}

Fuente: elaboración propia.

REVESCO No 109 - MONOGRÁFICO: La financiación complementaria y la respuesta de la economía social: la situación del "des-crédito" bajo la crisis financiera -

ISSN: 1885-8031 - www.ucm.es/info/revesco 
Figura 1.C

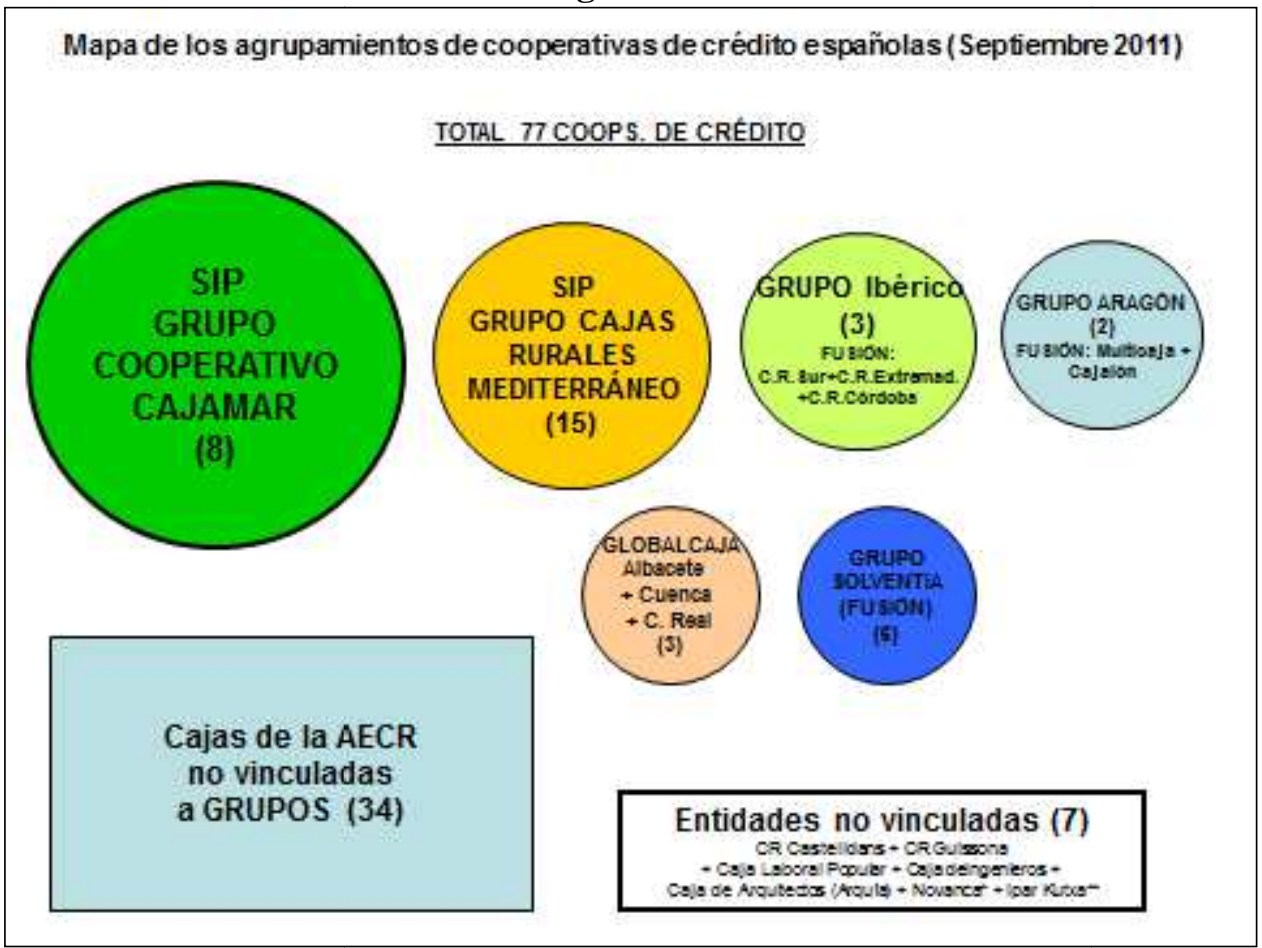

Fuente: elaboración propia.

Figura 1.D.

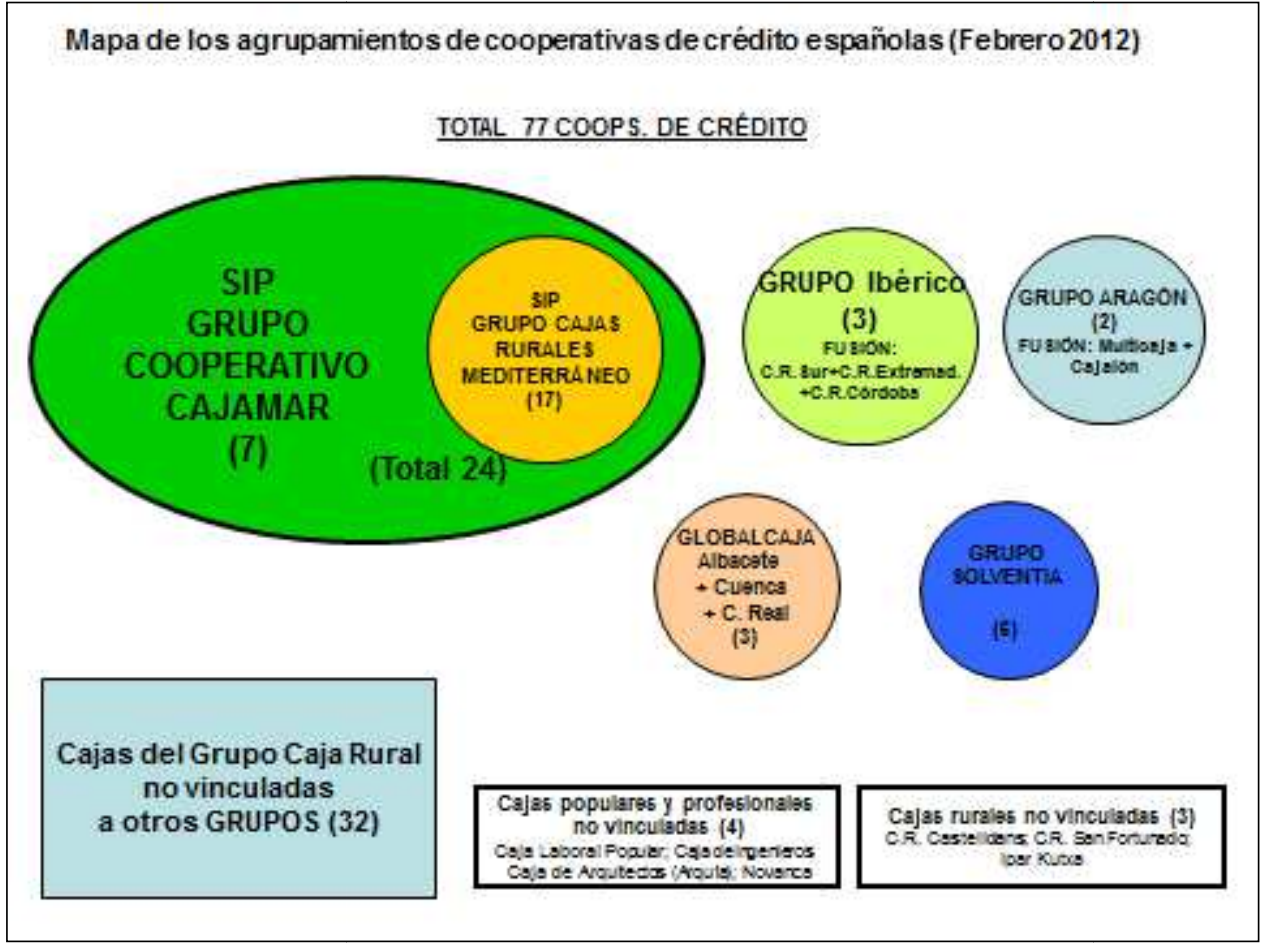

Fuente: elaboración propia.

REVESCO No 109 - MONOGRÁFICO: La financiación complementaria y la respuesta de la economía social: la situación del "des-crédito" bajo la crisis financiera -

ISSN: 1885-8031 - www.ucm.es/info/revesco 
Figura 1.E.

Mapa de los agrupamientos de cooperativas de crédito españolas (Mayo 2012)

TOTAL 77 COOPS. DE CREDITO

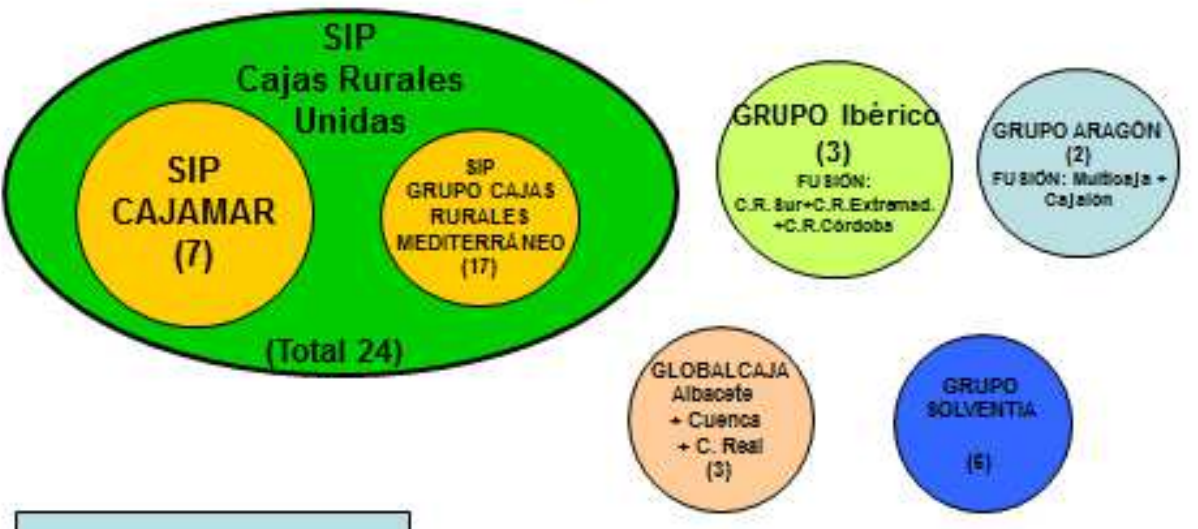

Cajas del Grupo Caja Rural novinculadas a otros GRUPOS (32)

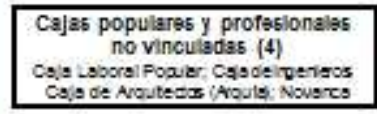
Cajas rurales no vinculadas [3]
CR. Cesselders CR. Senfonuredo loer Kuss

Fuente: elaboración propia.

Figura 1.F.

Mapa de los agrupamientos de cooperativas de crédito españolas (septiembre 2012) TOTAL 74 COOPS. DE CRÉDITO

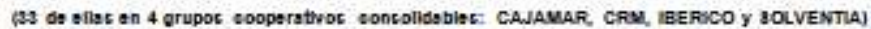

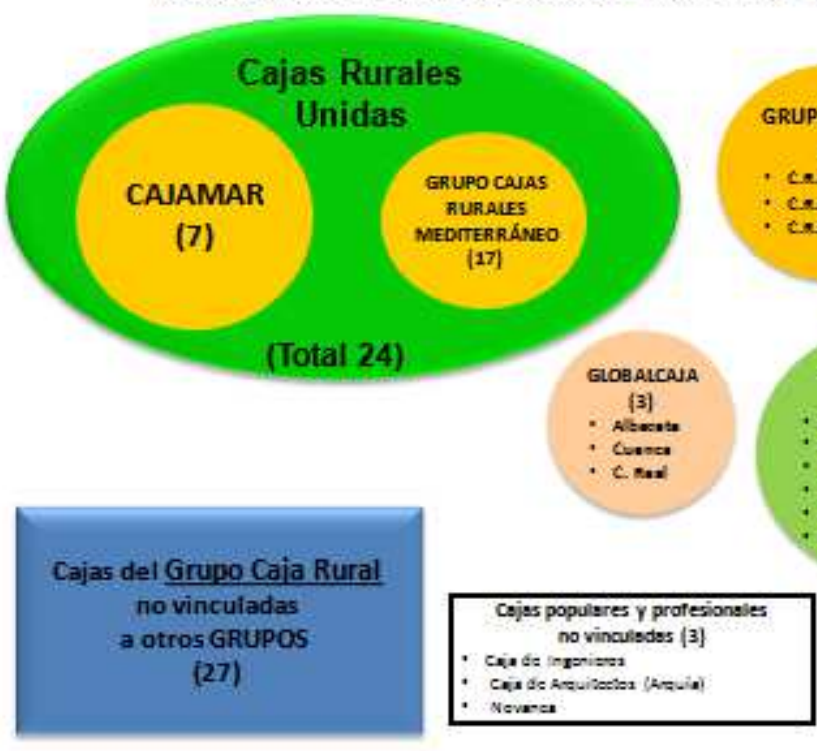

Fuente: elaboración propia.

REVESCO No 109 - MONOGRÁFICO: La financiación complementaria y la respuesta de la economía social: la situación del "des-crédito" bajo la crisis financiera -

ISSN: 1885-8031 - www.ucm.es/info/revesco 
Los sistemas institucionales de protección desarrollados por las cajas rurales españolas suponen un avance cualitativo en la consolidación del sector. Se han caracterizado como fusiones "frías" o "virtuales" pues pretenden el mantenimiento de la independencia jurídica de las entidades que los integran y, en particular, de su identidad territorial y comercial. A largo plazo, el SIP se puede traducir en el reforzamiento de las oportunidades en el mercado, la diversificación de productos y mercados, la integración de procesos y el reparto del mercado entre las cajas rurales participantes.

En cualquier caso, la configuración de los SIP y su desarrollo como unidad de decisión empresarial requiere homogeneidad en el modelo de negocio; pero también compatibilidad económica y financiera entre las integrantes, con independencia de su dimensión individual.

A la lógica pérdida de autonomía plena de gestión de cada entidad, se unen los costes de supervisión interna del grupo y la necesidad de salvaguardar el cumplimiento de los acuerdos contractuales para evitar posibles comportamientos oportunistas individuales al amparo de la protección del sistema.

Igualmente, se plantean serios problemas de unidad de acción y probablemente de elección de las entidades con más liderazgo cuando se trate de grupos más homogéneos. En otros casos, el SIP puede utilizarse como instrumento transitorio para futuras absorciones por parte de las entidades de mayor dimensión.

En el cualquier caso, los criterios de formación de los SIP entre las cajas rurales españolas tienen cierta correspondencia con su homogeneidad; pero no eluden otros criterios no económicos y de valoración tan subjetiva que sería muy difícil cuantificar; a saber: afinidades personales entre sus principales responsables; mejores relaciones tradicionales; posicionamientos estratégicos similares o compartidos en la actualidad y en el pasado; ausencia de rivalidad o conflictos anteriores; etc., lo cual ratifica la idea de que las operaciones de concentración empresarial no sólo pueden ser valoradas mediante indicadores puramente económicos. Los criterios personales son un factor clave.

Afortunadamente para el sector bancario español, el formado por las cooperativas de crédito, tiene una posición actual adecuada de solvencia y capitalización (Belmonte, 2007).

REVESCO No 109 - MONOGRÁFICO: La financiación complementaria y la respuesta de la economía social: la situación del "des-crédito" bajo la crisis financiera -

ISSN: 1885-8031 - www.ucm.es/info/revesco 
Ratios de morosidad comparativamente menores y también menor exposición a los riesgos que se han cebado sobre otras entidades financieras.

Un detalle de los procesos desarrollados en el sector hasta septiembre de 2012 es el recogido en la tabla 4.

Tabla 4: Resultados del proceso de concentración de las cooperativas de crédito (septiembre 2012)

\begin{tabular}{|c|c|c|c|c|}
\hline $\begin{array}{l}\text { RANKING } \\
\text { (ATM) }\end{array}$ & $\begin{array}{l}\text { DENOMINA } \\
\text { CIÓN } \\
\text { ASIGNADA }\end{array}$ & ENTIDADES INVOLUCRADAS & $\begin{array}{l}\text { TIPO DE } \\
\text { PROCESO DE } \\
\text { CONCENTRACI } \\
\text { ÓN }\end{array}$ & $\begin{array}{l}\text { ACTIVO } \\
\text { TOTAL } \\
(\text { miles de } \\
\text { €)* }\end{array}$ \\
\hline 1 & $\begin{array}{l}\text { CAJAS } \\
\text { RURALES } \\
\text { UNIDAS }\end{array}$ & $\begin{array}{l}\text { 1) Grupo cooperativo Cajamar: Cajamar C.R. + } \\
\text { C.R. de Casinos + Caixa Albalat + Caixa Petrer } \\
+ \text { Caixa Turís + C.R. Castellón + C.R. de } \\
\text { Canarias. Incluye la absorción por Cajamar de } \\
\text { C.R. Cmpo y C.R. Balears. } \\
\text { 2) Grupo CRM: Ruralcaja + C.R. Altea + C.R. S. } \\
\text { Roque de Almenara + C.R. de Callosa d'en Sarriá } \\
\text { + C.R. S. José de Burriana + C.R. Torrent + C.R. } \\
\text { S. Jaime Alquerías Niño Perdido + C.R. de } \\
\text { Cheste + C.R. S. José de Nules + C.R. de Villar + } \\
\text { C.R. la Junquera de Chilches + C.R. S. Josep de } \\
\text { Vilavella + C.R. S. Isidro de Vilafamés + C.R. de } \\
\text { Alginet + Crèdit Valencia. }\end{array}$ & $\begin{array}{c}\text { FUSIÓN } \\
\text { (Previa constitución } \\
\text { de dos SIP: Grupo } \\
\text { cooperativo Cajamar } \\
\text { y Grupo Cajas } \\
\text { rurales del } \\
\text { mediterráneo). }\end{array}$ & 43.936 .221 \\
\hline 2 & $\begin{array}{l}\text { GRUPO } \\
\text { IBÉRICO DE } \\
\text { CRÉDITO }\end{array}$ & $\begin{array}{l}\text { C.R. del Sur + C.R. de Extremadura + C.R. de } \\
\text { Córdoba. }\end{array}$ & SIP & 7.286 .003 \\
\hline 3 & $\begin{array}{l}\text { NUEVA CAJA } \\
\text { RURAL DE } \\
\text { ARAGÓN } \\
\text { (BANTIERRA) }\end{array}$ & $\begin{array}{c}\text { Multicaja (C.R. Aragonesa y de los Pirineos) + } \\
\text { Cajalón (C.R. de Aragón) }\end{array}$ & $\begin{array}{c}\text { FUSIÓN } \\
\text { (Previa fusión de CR } \\
\text { de Aragón y CR de } \\
\text { Campo de Cariñena; } \\
\text { y de Caja de los } \\
\text { Abogados y CR } \\
\text { Aragonesa y de los } \\
\text { Pirineos. }\end{array}$ & 6.023 .075 \\
\hline 4 & $\begin{array}{l}\text { GLOBALCAJ } \\
\mathbf{A}\end{array}$ & $\begin{array}{l}\text { CR Albacete + Cuenca + Ciudad Real. Incluye la } \\
\text { absorción por CR Albacete de CR La Roda }\end{array}$ & FUSIÓN & 4.788 .773 \\
\hline 6 & $\begin{array}{l}\text { En proceso } \\
\text { (desde marzo } \\
\text { 2012) }\end{array}$ & $\begin{array}{c}\text { C.R. Fuentepelayo + C.R. Burgos + C.R. Segovia } \\
+ \text { C.R. Castelldans }\end{array}$ & FUSIÓN & 1.424 .444 \\
\hline 5 & $\begin{array}{l}\text { GRUPO } \\
\text { SOLVENTIA }\end{array}$ & $\begin{array}{l}\text { C.R. de Almendralejo + C.R. de Utrera + C.R. } \\
\text { Baena Ntra. Sra. De Guadalupe + C.R. Ntra. Sra. } \\
\text { Del Rosario + C.R. de Cañete de las Torres Ntra. } \\
\text { Sra. Del Campo + C.R. Ntra. Madre del Sol. }\end{array}$ & SIP & 1.115 .437 \\
\hline 7 & $\begin{array}{l}\text { En proceso } \\
\text { (desde julio } \\
\text { 2012) }\end{array}$ & Caja Laboral Popular + Ipar Kutxa Rural & FUSIÓN & 24.605 .407 \\
\hline
\end{tabular}

* Las cifras de activos totales hacen referencia a diciembre del año 2011 por ser éste el último del que se disponen datos oficiales.

Fuente: Elaboración propia a partir de comunicados de las entidades, Anuario Estadístico de la Unacc y prensa económica.

REVESCO Nº 109 - MONOGRÁFICO: La financiación complementaria y la respuesta de la economía social: la situación del "des-crédito" bajo la crisis financiera -

ISSN: 1885-8031 - www.ucm.es/info/revesco 


\section{CONCLUSIONES.}

La actual y ya persistente crisis económica ha sacudido los cimientos del sistema económico y, en especial del sistema financiero, lo que exige una reflexión acerca de los errores que se han cometido y un replanteamiento de las estrategias empresariales para hacer frente a la nueva situación creada.

El perjuicio ocasionado por la crisis financiera al sector real ha sido contundente. La contracción crediticia y sequía de liquidez han llevado a una necesaria reducción del apalancamiento empresarial, motor de su rentabilidad. La relativa ausencia de fuentes alternativas de financiación para las empresas no cotizadas ha confirmado la extrema dependencia de éstas de un sistema demasiado bancarizado que no alentó el recurso a los mercados por parte de las pequeñas y medianas empresas.

Las reformas del sector financiero impuestas desde el inicio de la crisis han supuesto más presión para el sector bancario, a lo que se ha añadido la llamada tercera reforma de finales de agosto de 2012.

Estas reformas están teniendo un efecto social muy amplio que abunda en un "descrédito" del sector financiero que se suma al "descrédito" por la restricción financiera que se impone a empresas y familias.

La crisis financiera ha impactado sobre los tres tipos de entidades bancarias de forma diversa: el sector de la banca se ha visto afectado especialmente en el ámbito de las entidades más centradas en el negocio doméstico; las cajas de ahorros son el segmento más afectado por la crisis; si bien, es cierto que algunas de ellas (una minoría), gracias a una prudente gestión de los riesgos en el pasado mantienen buenos niveles de solvencia. En el sector de las cajas de ahorros se han producido diversos episodios de intervención pública. Las cooperativas de crédito, por el contrario, aunque igualmente han desarrollado un intenso proceso de reagrupamiento, principalmente mediante la formación de sistemas institucionales de protección y/o grupos cooperativos, son las menos afectadas del sector bancario español.

La enorme fragmentación del sector previa a la crisis, hacía necesarios procesos de concentración que redujesen el número de entidades para lograr aumentar su eficiencia y reforzar su solvencia mediante la introducción de mejoras en sus mecanismos de control y REVESCO No 109 - MONOGRÁFICO: La financiación complementaria y la respuesta de la economía social: la situación del "des-crédito" bajo la crisis financiera -

ISSN: 1885-8031 - www.ucm.es/info/revesco 
gestión de riesgos; y para garantizar la viabilidad y solidez de las entidades del sistema financiero, incrementando así la confianza de los agentes económicos en el mismo.

En este escenario de necesaria reestructuración bancaria forzada, el SIP aparece como un proyecto estratégico, quizá como paso previo a fusiones.

Los SIP desarrollados por las entidades financieras españolas han supuesto un primer intento por dinamizar y concentrar el sector, pero al no ser procesos plenos de integración, han ocasionado no pocas fricciones en su coordinación y fracasos en diversos casos. Se han caracterizado como fusiones "frías" o "virtuales" pues pretenden el mantenimiento de la independencia jurídica de las entidades que los integran y, en particular, de su identidad territorial y comercial.

La dificultad de coordinación entre entidades con estrategias distintas derivadas de su dimensión y objetivos podría solucionarse supuestamente encontrando vectores comunes de comportamiento y planes estratégicos.

Este contexto es el que configura las dos facetas señaladas en el trabajo: el descrédito social por lo ocurrido, en parte como consecuencia de las malas prácticas de algunas entidades; y el "des-crédito" por las graves restricciones a la financiación de empresas, autónomos y familias.

\section{BIBLIOGRAFÍA.}

ÁLVAREZ, J.A. La banca española ante la crisis financiera. Estabilidad Financiera, $\mathrm{n}^{\mathrm{o}}$ 15, 2008, p. 21-38.

AMEL, D.; BARNES, C.; PANETTA, F. Y SALLEO, C. Consolidation and efficiency in the financial sector: a review of the international evidence. Journal of Banking and Finance, $n^{\circ} 28$ (10), 2004, p. 2493-2519.

BANCO DE ESPAÑA. Boletín Estadístico. Madrid: Banco de España, varios años.

BELMONTE, L.J. El sector de las cooperativas de crédito en España. Un estudio por comunidades autónomas. Sevilla: Publicaciones CES Andalucía, 2007.

REVESCO No 109 - MONOGRÁFICO: La financiación complementaria y la respuesta de la economía social: la situación del "des-crédito" bajo la crisis financiera -

ISSN: $1885-8031$ - www.ucm.es/info/revesco 
BERGÉS, A. Bancos y cajas: estrategias divergentes. Análisis, no 112, 2003, p. 5-20.

BERGÉS, A. Y GARCÍA, A. Las entidades de crédito ante la crisis. Economistas, no 119 , 2009, p. 139-150.

CALVO, A. Y PAUL, J. Las cajas de ahorro y las cooperativas de crédito ante la crisis: evolución en su presencia territorial y en su operativa. REVESCO, Revista de Estudios Cooperativos, $n^{\circ}$ 100-Extraordinario 2010 Monográfico: La respuesta de la Economía Social ante una crisis global, 2010, p. 68-100.

CALVO, A.; PAREJO, J.A.; RODRÍGUEZ, L. Y CUERVO, A. Manual de sistema financiero español. 22a edición actualizada. Madrid: Editorial Ariel Economía, 2010.

CARRASCO, I. La ética como eficiencia: la responsabilidad social en las cooperativas de crédito españolas. CIRIEC-España, Revista de Economía Pública, Social y Cooperativa, $\mathrm{n}^{\circ} 53,2005$, p. 351-367.

CASTELLÓ, E. Dirección y organización de entidades financieras. Madrid: ESIC, 1996.

CHAVES, R. Y SOLER, F. El gobierno de las cooperativas de crédito en España. Valencia: CIRIEC-España, 2004.

CONFEDERACIÓN ESPAÑOLA DE CAJAS DE AHORROS. Anuario estadístico de las cajas de ahorros. Madrid: CECA, varios años.

FUENTELSAZ, L.; GÓMEZ, J. Y PALOMAS, S. La reestructuración de la red de oficinas en el sector bancario español: 1995-2005. Papeles de Economía Española, nº 114, 2008, p. 173-189.

GUTIÉRREZ, M. Análisis del desempeño en la reordenación del sistema bancario español: el caso de las cajas de ahorros. Madrid: Universidad Nacional de Educación a Distancia, 2011.

GUTIÉRREZ, M.; PALOMO, R.; ROMERO, M. La expansión territorial como factor motivador de la reestructuración del sistema financiero español: el caso de las cajas de ahorros y las cooperativas de crédito. REVESCO, Revista de Estudios Cooperativos, $\mathrm{n}^{\circ}$ 107, 2012, p. 7-34.

MARCO, A. Y MOYA, I. Factores que inciden en la eficiencia de las entidades de crédito cooperativo. Revista Española de Financiación y Contabilidad, n 105,2000 , p. 781-808.

MELIÁN, A. Y SANCHIS, J. R. Expansión y crecimiento de las cooperativas de crédito durante el período 1993-2007 en la Comunidad Valenciana. REVESCO, Revista de Estudios Cooperativos, no 98, 2009, p. 97-117.

REVESCO No 109 - MONOGRÁFICO: La financiación complementaria y la respuesta de la economía social: la situación del "des-crédito" bajo la crisis financiera -

ISSN: 1885-8031 - www.ucm.es/info/revesco 
MORCATE, C., FUENTELSAZ, L. Y GÓMEZ, J. El efecto temporal en el resultado de las fusiones y adquisiciones: el caso de las cajas de ahorros españolas. Revista Europea de Dirección y Economía de la Empresa, no 18 (4), 2009, p. 49-68.

PALOMO, R.J. Análisis empírico del criterio de territorialidad en la actividad de las cajas rurales españolas. Revista Europea de Dirección y Economía de la Empresa, $\mathrm{n}^{\circ} 8$ (2), 1999, p. 41-62.

PALOMO, R.J. Y MATEU, J.L. Verificación de la aplicación del criterio de territorialidad en las cajas rurales españolas, CIRIEC-España, Revista de Economía Púbica, Social y Cooperativa, $\mathrm{n}^{\circ} 32,1999$, p. 157-188.

PALOMO, R. Y GONZÁLEZ, M. Un contraste de la divergencia en el modelo de negocio de las entidades financieras de economía social: cajas de ahorros y cooperativas de crédito, REVESCO, Revista de estudios cooperativos, $\mathrm{n}^{\circ}$ 83, 2004, p. 85-114.

PALOMO, R. Y SANCHIS, J.R. Un análisis del crédito cooperativo en España: situación actual, expansión territorial y proyección estratégica. Estudios de Economía Aplicada, no 26 (1), 2008, p. 89-132.

PALOMO, R. Y SANCHIS, J.R. Efectos de las fusiones sobre la concentración y la eficiencia bancaria: el caso de las cajas rurales y los retos de la crisis financiera, Revista Española de Financiación y Contabilidad, vol.39 (146), 2010, pp. 291-321.

PALOMO, R.; SANCHIS, J.R. Y GUTIÉRREZ, M. Efectos de la crisis financiera sobre la innovación en la reorganización de los sistemas bancarios: los sistemas institucionales de protección en las entidades financieras de ámbito territorial. Revista Innovar Journal, 2011, vol. 21 (39).

RUIZ, A. Financial Systems and Banking Crises: an assessment, Revista Mexicana de Economía y Finanzas, n 5(1), 2006, pp. 13-27.

SANCHIS, J.R. Análisis estratégico de las cooperativas de crédito. Estudio empírico aplicado a las cajas rurales de la Comunidad Valenciana, Información Comercial Española, $\mathrm{n}^{\mathrm{o}} 805$, 2003, pp. 145-169.

SANCHIS, J.R. Y CAMPS, J. Dirección estratégica bancaria. Madrid: Ediciones Díaz de Santos, 2003.

SANCHIS, J.R., HERRERA, J. Y SORIANO, J.F. Un estudio sobre la estructura organizativa y de RR.HH. de las cooperativas de crédito de la Comunidad Valenciana, CIRIECEspaña, Revista de Economía Pública, Social y Cooperativa, no 36, 2000, pp. 147-178.

REVESCO No 109 - MONOGRÁFICO: La financiación complementaria y la respuesta de la economía social: la situación del "des-crédito" bajo la crisis financiera -

ISSN: 1885-8031 - www.ucm.es/info/revesco 
TORRERO, A. La crisis financiera internacional y económica española, Madrid: Ediciones Encuentro, 2008.

UNIÓN NACIONAL DE COOPERATIVAS DE CREDITO. Anuario de las cajas rurales y cooperativas de crédito en España. Madrid: UNACC, varios años.

REVESCO No 109 - MONOGRÁFICO: La financiación complementaria y la respuesta de la economía social: la situación del "des-crédito" bajo la crisis financiera -

ISSN: 1885-8031 - www.ucm.es/info/revesco 